\title{
Changes in calmodulin level and cAMP-dependent protein kinase activity during epididymal maturation of ram spermatozoa
}

\author{
C. C. Pariset*†, J. M. F. Feinberg*, J. L. Dacheux $\ddagger$ and S. J. Weinman*† \\ ${ }^{*} U$.E.R. Biomédicale des Saints-Pères, 45 rue des Saints-Pères, 75270 Paris Cedex 06; $\dagger$ Faculté de \\ Médecine Saint-Antoine, 27, Rue Chaligny, 75571 Paris Cedex 12; and $\ddagger$ Laboratoire de Physiologie \\ de la Reproduction, INRA, 37380 Monnaie, France
}

\begin{abstract}
Summary. Calmodulin concentration and cAMP-dependent protein kinase activity were simultaneously determined on ram spermatozoa collected by cannulation of successive segments of the epididymal tubule. Epididymal transit was characterized on one hand by an overall decrease in the calmodulin level and on the other by a dramatic rise in the cAMP-dependent protein kinase activity. In contrast to the calmodulin level, the cAMP-dependent protein kinase activity was correlated with the acquisition of flagellar beat. No further alterations in the level of these two proteins could be detected as spermatozoa acquired progressive motility.
\end{abstract}

\section{Introduction}

Considerable information is now available concerning the regulatory mechanisms of some of the main biological events which are specific to mammalian spermatozoa. It is now well established that intracellular $\mathrm{Ca}^{2+}$ and cAMP are involved in the regulation of these processes. In particular, the antagonist action of intracellular $\mathrm{Ca}^{2+}$ and cAMP on sperm motility substantiates the hypothesis of a concerted regulation of flagellar beat by these two ubiquitous messengers (Tash \& Means, 1982, 1983).

The action of cAMP and $\mathrm{Ca}^{2+}$ is mediated through their binding to specific proteins: the regulatory subunit of the cAMP-dependent protein kinase (protein kinase A), and the calcium binding proteins, respectively. Protein kinase A and calmodulin have been characterized in sperm extracts (Hoskins, Casillas \& Stephens, 1972; Garbers, Hansbrough, Radany, Hyne \& Kopf, 1980; Feinberg et al., 1981) and localized within the cells by indirect immunofluorescence (Jones, Lenz, Palewitz \& Cormier, 1980; Feinberg et al., 1981; Tash \& Means, 1982). Moreover, it has been shown (Feinberg et al., 1983) that a decrease in calmodulin content occurs during spermatogenesis whereas the cAMP-dependent protein kinase activity increased during epididymal maturation of spermatozoa. Pariset, Roussel, Weinman \& Demaille (1983) have demonstrated that the extractable cAMP-dependent protein kinase activity is positively correlated with the percentage of motile cells in samples of human semen.

The acquisition of fertilizing ability in mammalian spermatozoa depends on alterations that occur during epididymal transit. The corpus epididymidis is a critical region, especially for the development of fertilizing ability and sperm motility (Dacheux \& Paquignon, 1980; Orgebin-Crist, Olson \& Danzo, 1981). It was therefore felt that changes in the intracellular levels of calmodulin and protein kinase $A$ activity might reflect the ontogeny of calcium and cAMP regulations during sperm epididymal maturation. We have therefore determined total calmodulin and protein kinase A activity levels in sperm samples collected from successive segments of the epididymis. 


\section{Materials and Methods}

Sperm cell preparation. Epididymides were obtained from 7 adult rams (Ile-de-France) during the breeding season. Sperm samples from 10 different segments of the epididymis were collected by perfusion of small areas of the organ by the method described by Dacheux (1980). The samples were diluted in Krebs-Ringer-bicarbonate (KRB) (Imai, Niwa \& Iritani, 1977), to a final concentration of $10^{7}$ spermatozoa $/ \mathrm{ml}$.

Motility determination. The motility of the spermatozoa was estimated on aliquants as the percentage of motile spermatozoa after a 10 -min incubation at $37^{\circ} \mathrm{C}$ in a $0.1 \mathrm{~mm}$ depth cell before agglutination has begun (Dacheux, Paquignon \& Combarnous, 1983). This value was determined by Doppler velocimetry using the SORO 200 spectrokinesimeter (SORO Arcueil, France), as described by Dubois et al. (1975) and Dacheux et al. (1983).

The sperm samples were centrifuged for $10 \mathrm{~min}$ at $1200 \mathrm{~g}$ at room temperature and the sperm pellet was quickly frozen and kept at $-70^{\circ} \mathrm{C}$ until assay which was performed within a few days.

In a separate experiment, sperm motility induction was investigated according to the methods previously described (Dacheux \& Paquignon, 1980). Spermatozoa collected by cannulation and perfusion from the rete testis, caput and cauda epididymidis of 2 adult rams (Ile-de-France) were incubated in citrate-bicarbonate-egg yolk buffer in the presence of $5 \mu \mathrm{M}$-caffeine or in KRB for 10 $\min$ at $37^{\circ} \mathrm{C}$. At the end of the incubation period, aliquants of the different sperm suspensions were scored for motility as described above. Meanwhile, the sperm suspensions were centrifuged at $1200 \mathrm{~g}$ for $10 \mathrm{~min}$ and the pellets were immediately frozen and stored at $-70^{\circ} \mathrm{C}$ until assay.

Materials. Histone II AS mixture from calf thymus and cAMP were from Sigma Chemical Co. (St Louis, MO, U.S.A.), P81 phosphocellulose and 3MM papers from Whatman Inc. (Clifton, NJ, U.S.A.). Theophylline was a gift of Bruneau Laboratories (Paris, France). $\left[\gamma^{-32}\right.$ P]ATP was prepared according to Glynn \& Chappell (1964) using carrier-free [ ${ }^{32}$ P]orthophosphoric acid purchased from New England Nuclear (Boston, MA, U.S.A.). Myosin light chains were prepared from rabbit skeletal muscle myosin according to Perrie \& Perry (1970). The phosphorylatable light chain was purified and freed from contaminating calmodulin from the whole light chain fraction as described by Maita, Umegane, Kato \& Matsuda (1980). Light chain kinase from skeletal myofibrillar myosin was extracted from canine leg muscles and partly purified by ion-exchange chromatography on DEAE Sepharose using the procedure described by Walsh, Vallet, Cavadore \& Demaille (1980); it was found to be strictly $\mathrm{Ca}^{2+}$-dependent and specific for calmodulin that could not be substituted by other calcium-binding proteins, such as troponin $\mathrm{C}$ and parvalbumin. Ram testis calmodulin was purified by the method of Autric, Ferraz, Kilhofer, Cavadore \& Demaille (1980). All other reagents used in this study, purchased from Merck Inc. (Darmstadt, West Germany), were of the highest grade available.

Sperm homogenization. Sperm pellets were thawed and resuspended to $2 \times 10^{8}$ spermatozoa $/ \mathrm{ml}$ in ice-cold $15 \mathrm{~mm}$-2-mercaptoethanol, $4 \mathrm{mM}$-EDTA, $15 \mathrm{~mm}$-Tris- $\mathrm{HCl}$ buffer, $\mathrm{pH} \mathrm{7.5,} \mathrm{containing} 0.2$ mM-phenylmethylsulphonyl fluoride and 10 units aprotinin $/ \mathrm{ml}$ as antiproteolytic agents. The suspension was then homogenized with a glass homogenizer and sonicated at $25 \mathrm{~W}$ for nine $15-\mathrm{sec}$ bursts.

Calmodulin assay. Calmodulin was assayed in each sperm homogenate after trichloroacetic acid treatment (Haiech, Klee \& Demaille, 1981). The concentrations of $\mathrm{CaCl}_{2}$ and trichloroacetic acid in the sonicate were adjusted to be $5 \mathrm{~mm}$ and $4 \%(\mathrm{w} / \mathrm{v})$ respectively. The suspension was allowed to stand for $5 \mathrm{~min}$ on ice and then neutralized by addition of $1 \mathrm{M}$-Tris. Finally, the $25000 \mathrm{~g} 30 \mathrm{~min}$ supernatant was assayed for calmodulin by the activation of myosin light chain kinase in the presence of calcium according to Le Peuch, Ferraz, Walsh, Demaille \& Fischer (1979).

Protein kinase $A$ assay. Total protein kinase activity was measured on $20 \mu \mathrm{l}$ samples of the $25000 \mathrm{~g}$ supernatant of the sonicate in a final volume of $70 \mu \mathrm{l}$ with histone II AS mixture from calf 
thymus as a substrate, in the following incubation medium: $4.2 \mathrm{mg}$ histone II AS/ml, $0.3 \mathrm{~mm}$ ethylene glycol-bis-(-aminoethyl-ether)- $N, N^{\prime}$-tetraacetic acid (EGTA), $3 \mathrm{~mm}$-theophylline, $0.7 \mathrm{mM}$ dithiothreitol (DTT), 4.3 mM-magnesium acetate, $7 \cdot 1 \mathrm{~mm}$-sodium fluoride, $7 \cdot 14 \mu \mathrm{M}$-cAMP and 0.14 mM-[ $\gamma^{-32}$ P]ATP (200 d.p.m./pmol), $35 \mathrm{mm-phosphate} \mathrm{buffer,} \mathrm{pH} \mathrm{7.0.} \mathrm{At} \mathrm{the} \mathrm{end} \mathrm{of} \mathrm{the} \mathrm{8-min}$ incubation period at $30^{\circ} \mathrm{C}, 50 \mu \mathrm{l}$ of each incubation medium were transferred to $\mathrm{P} 81$ phosphocellulose filters $(1 \times 2 \mathrm{~cm})$. Papers were washed according to Witt \& Roskoski (1975) and the radioactivity was determined on each filter by liquid scintillation counting. The protein kinase activity was defined as ${ }^{32} \mathrm{PO}_{4}$ incorporated per min from $\left[\gamma^{32} \mathrm{P}\right] \mathrm{ATP}$ into histone between otherwise identical assays performed in the presence or absence of cAMP. The activity of cAMPindependent kinase was measured by performing an otherwise identical assay in the absence of cAMP. cAMP-dependent protein kinase activity was defined as the difference between the total kinase activity (assay with cAMP) and the cAMP-independent activity (assay in absence of cAMP). Determinations were performed in duplicate on serial dilutions of each sample until a plateau for the enzyme activity was reached, to eliminate any interference due to the presence of inhibitors in the original sample.

\section{Results}

The percentage of motile spermatozoa in the cell populations collected from different regions of the epididymis of 6 animals is shown in Text-fig. 1. The motility pattern, as observed by microscopic observation of the samples, showed qualitative changes correlated to the origin of the different sperm samples. For spermatozoa from the posterior caput, the only detectable movement was a flagellar oscillation and very few $(1 \%)$ spermatozoa showed progressive movement, even after a 10 min incubation at $37^{\circ} \mathrm{C}$. For spermatozoa from the corpus epididymidis, the vibration of the flagella increased and the gametes moved with a circular or irregular pattern of progression. The head exhibited a rotatory movement out of phase with the flagellar beat. A forward progression and straight line movement of the gamete appeared in zones 8,9 and 10.

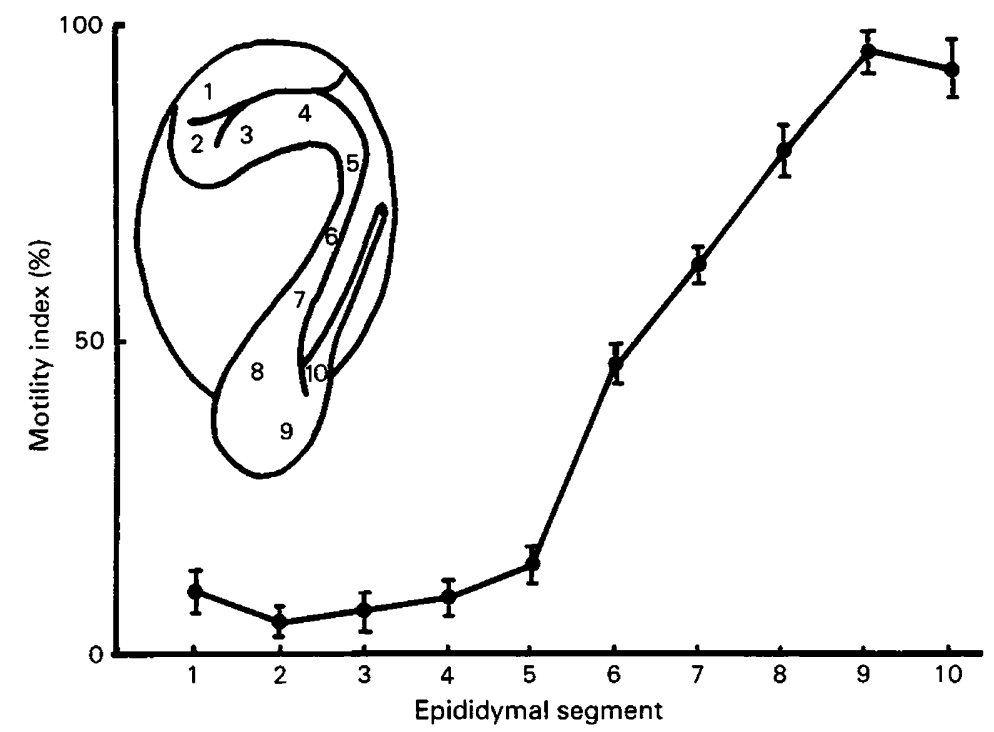

Text-fig. 1. Motility of ram spermatozoa during epididymal transit. Values are the mean \pm s.e.m. of the measurements made on 6 rams. The drawing shows the epididymal segments from which spermatozoa were collected by cannulation. Segments $1-4$ correspond to the caput, 5-7 to the corpus and 8-10 to the cauda epididymidis. 
As shown in Text-fig. 2, sperm calmodulin level and cAMP-dependent protein kinase activity varied during epididymal transit. The maximum concentration of intracellular calmodulin was reached in spermatozoa collected from segments 2 and 3 of the ram epididymis. The value then decreased in spermatozoa collected from subsequent segments of the epididymal tubule. By contrast, the sperm-extractable cAMP-dependent protein kinase activity greatly increased between spermatozoa collected from regions 3 and 5 of the epididymis. The kinase activity remained steady in spermatozoa collected from segments 6-10. The increase in the cAMPdependent protein kinase activity was associated with a progressive rise in the ratio of the protein kinase activity recorded in the absence $(-)$ and presence $(+)$ of $10 \mu \mathrm{M}-\mathrm{cAMP}$, the lowest $(0 \cdot 18)$ and highest (0.58) values being obtained in segments 1 and 9 of the epididymis respectively (data not shown).

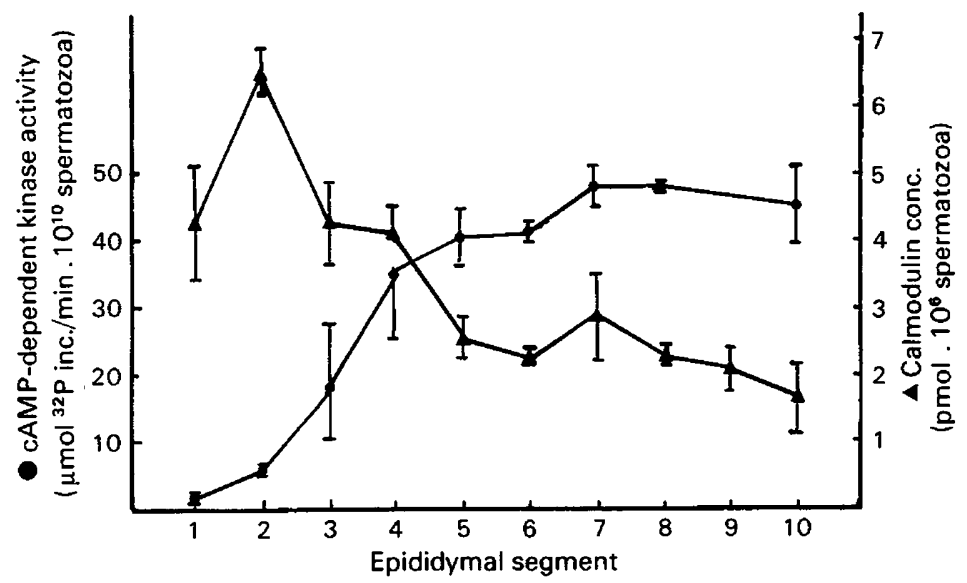

Text-fig. 2. Sperm calmodulin intracellular concentration $(\boldsymbol{\Lambda})$ and cAMP-dependent protein kinase activity $(O)$ during epididymal transit. Values are the mean \pm s.e.m. of closely agreeing triplicate determinations made on 6 animals.

(a)

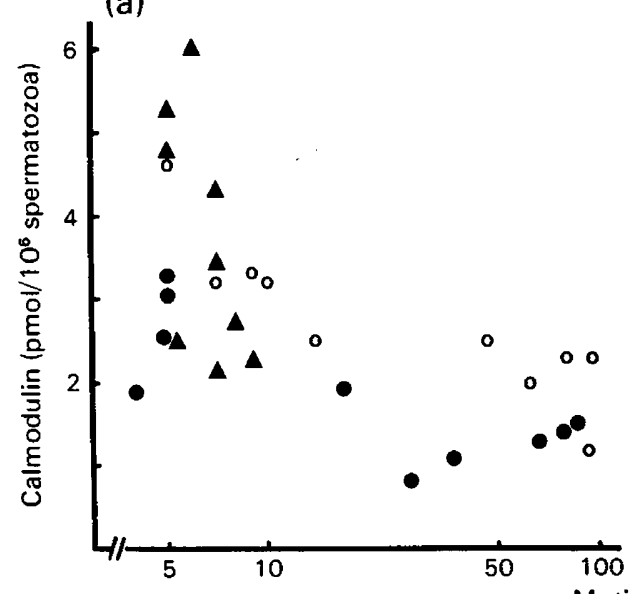

(b)

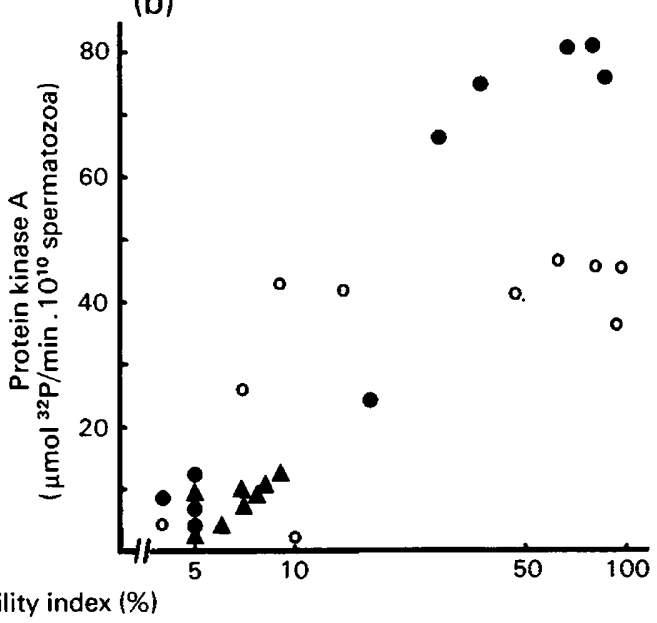

Text-fig. 3. Correlations between the motility index of ram epididymal sperm populations and (a) calmodulin intracellular concentration, (b) cAMP-dependent protein kinase activity. (O) $(\Lambda)(O)$ refer to different animals. 
The sperm calmodulin concentration and cAMP-dependent protein kinase activity both varied as a function of the percentage of motile spermatozoa in the different samples. For example, sperm samples with a motility index of about $10 \%$ exhibited the highest calmodulin levels and the lowest kinase activities, whereas high motility samples showed the lowest calmodulin concentrations and the highest kinase activities. A linear correlation could not be demonstrated between the calmodulin level and the motility index of the sperm samples (Text-fig. 3). However, a positive correlation was demonstrated between the motility index (up to $35 \%$ ) and the cAMP-dependent protein kinase activity ( $r=0.90, n=21$, as determined by the least squares method).

In an abnormal animal, in which epididymal transit was not associated with any detectable acquisition of sperm motility, the calmodulin levels followed the same pattern of change during

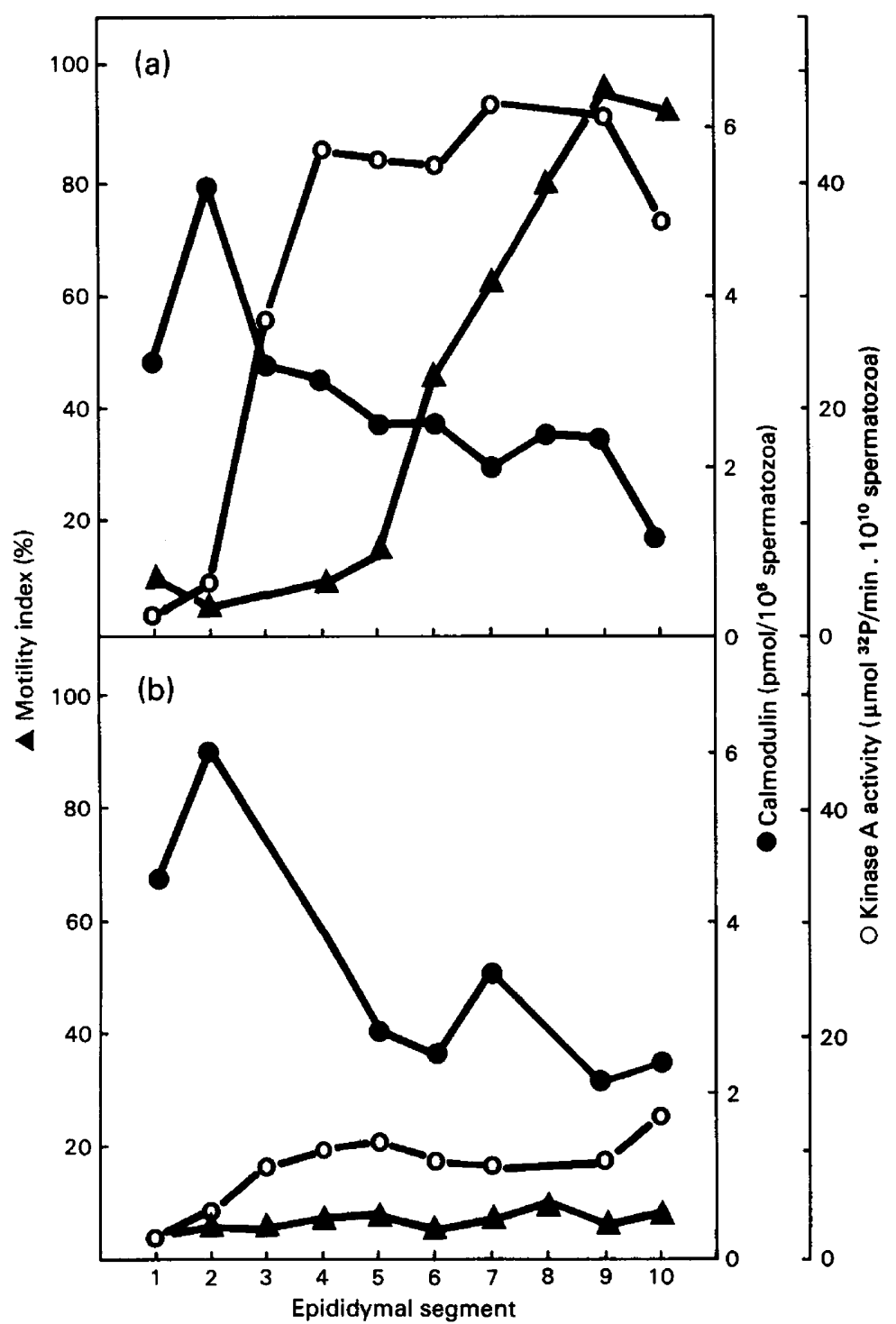

Text-fig. 4. Calmodulin concentration (O) and cyclic AMP-dependent protein kinase activity $(O)$ in (a) a control ram and (b) a ram with an abnormally low sperm motility index. 
epididymal transit as in the control animals, but there was little increase in the kinase activity (Text-fig. 4).

The initiation of flagellar motility of spermatozoa from the rete testis or caput epididymidis by incubation in the citrate-bicarbonate-egg yolk buffer caffeine medium was associated with an increase in the cAMP-dependent protein kinase activity and a rise in the cAMP( $(-) v s \mathrm{cAMP}(+)$ protein kinase activity ratio (Table 1 ).

Table 1. cAMP-dependent protein kinase activity and induction of motility of ram spermatozoa

\begin{tabular}{|c|c|c|c|c|c|c|c|c|c|}
\hline \multirow[b]{3}{*}{ Medium* } & \multicolumn{9}{|c|}{ Spermatozoa from: } \\
\hline & \multicolumn{3}{|c|}{ Rete testis } & \multicolumn{3}{|c|}{ Caput epididymidis } & \multicolumn{3}{|c|}{ Cauda epididymidis } \\
\hline & a & $b$ & c & a & $\mathbf{b}$ & c & $\mathbf{a}$ & $\mathrm{b}$ & c \\
\hline KRB & $4 \cdot 1$ & 0.35 & 0 & $19 \cdot 3$ & 0.45 & 10 & $40 \cdot 6$ & 0.47 & 90 \\
\hline CBY & $23 \cdot 9$ & 0.55 & 62 & $45 \cdot 1$ & 0.53 & 85 & $54 \cdot 3$ & 0.66 & 90 \\
\hline
\end{tabular}

(a) cAMP-dependent protein kinase activity ( $\mu \mathrm{mol}\left[{ }^{32} \mathrm{P}\right]$ incorporated/min per $10^{10}$ spermatozoa).

(b) cAMP(-) us cAMP(+) protein kinase activity ratio.

(c) Percentage of motile cells.

* Krebs-Ringer-bicarbonate (KRB) or citrate-bicarbonate-egg yolk (CBY); incubation for $10 \mathrm{~min}$ at $37^{\circ} \mathrm{C}$ (see text).

\section{Discussion}

Our results show that the activities of both calmodulin and protein kinase A change dramatically in ram spermatozoa during epididymal transit, at this time of sperm maturation when motility patterns also change dramatically (Dacheux et al., 1983). The changes in calmodulin and protein kinase activities confirm the observations made by Feinberg et al. (1983).

The data must be viewed in the light of current dogma which believes the sperm cell to be essentially inert with respect to protein synthesis and degradation. Several pieces of evidence demonstrate that the patterns of activity observed did indeed reflect changes in the total cellular activity of both calmodulin and protein kinase A. Determinations of levels of either were in all cases identical when performed on sperm sonicates or extracts (data not shown). Moreover, the strictly calmodulin-specific enzymic assay was performed on cell homogenates after a $4 \%$ trichloroacetic acid treatment. In these experimental conditions, the affinity of calmodulin for calcium was decreased and most of the potential interfering proteins were denatured. Calmodulin, which was thus freed from enzyme systems or cell organelles, could be selectively solubilized by the addition of base to a neutral pH. Moreover, preliminary controls showed that, on homogenates of spermatozoa collected from different segments of the epididymis, the TCA. treatment of the sonicates ensured a nearly quantitative extraction of calmodulin. It was found that, in all cases, only a very low amount of calmodulin ( $<4 \%$ of the total calmodulin content) could be recovered after solubilization of the final $25000 \mathrm{~g}$ pellet in the presence of $100 \mathrm{~mm}-\mathrm{KCl}$ and $1 \%$ Triton X-100. Therefore, as observed by Kakiuchi et al. (1982), changes in the calmodulin levels could not be accounted for by the translocation of calmodulin between the soluble and particulate fractions.

It is known that the protein kinase A system involves a catalytic subunit $\mathrm{C}$, mostly soluble, and a regulatory subunit $R$, mostly particulate; the $C$ subunit is active when soluble and free, but in the absence of cAMP it binds to the $\mathrm{R}$ subunit to form an inactive complex $\mathrm{RC}$, also mostly particulate; in the presence of $\mathrm{CAMP}$, the RC complex dissociates, thereby liberating the $\mathrm{C}$ subunit which becomes active once more (see Horowitz, Toeg \& Orr, 1984). No significant differences in the intracellular cAMP levels could be observed in spermatozoa collected from successive segments of 
the epididymis. The changes observed in the protein kinase $\mathrm{A}$ activity could not therefore be accounted for by changes in cAMP-induced dissociation (and solubilization) of the catalytic subunit $\mathrm{C}$ from pre-existing bound $\mathrm{RC}$ complex.

Clearly, therefore, during sperm maturation there is an abrupt and large decrease in calmodulin activity, and an even greater increase in protein kinase A activity. Much experimentation will be required to explain this. The decrease in calmodulin activity could be due to selective protein degradation, to selective loss (release) from the sperm cell, or to an hitherto unknown form of sequestration. The increase in protein kinase activity could result from hitherto unsuspected denovo synthesis of specific protein, or from specific protein modification. The increase of both the cAMP-dependent activity $(\mathrm{RC})$ and the ratio of $\operatorname{cAMP}(-)$ : $\operatorname{cAMP}(+)$ activity $(\mathrm{C} / \mathrm{RC}+\mathrm{C})$ indicate that the $R$ and $C$ subunits are involved, but the changes can apparently be induced within about $10 \mathrm{~min}$ (see Table 1; dramatic increases in protein kinase activity were noted after only 10 min incubation of spermatozoa in citrate-bicarbonate-egg yolk medium). This latter observation would seem to preclude the involvement of de-novo protein synthesis.

The maturational acquisition of motility takes place in two phases. The onset of flagellar beating is seen as the spermatozoa pass through the anterior part of the corpus epididymidis, whereas the progressive motility pattern develops as the spermatozoa enter the distal region of the cauda epididymidis. While the development of the progressive motility pattern occurs without any detectable change in the protein kinase A activity, the onset of flagellar beating is closely related to the dramatic increase in the activity that occurred when spermatozoa entered the corpus epididymidis. The direct involvement of the cAMP-dependent protein kinase activity in generating flagellar beat is substantiated by the fact that no increase in the kinase activity could be detected in the low motility sperm samples collected from the abnormal animal. In addition, the induction of motility in vitro in spermatozoa from the rete testis or caput epididymidis was associated with a marked increase in the enzyme activity.

The present data would fit with previous observations made by Tash \& Means (1982) demonstrating a close correlation between cAMP-dependent stimulation of flagellar motility and enhanced phosphorylation of specific sperm proteins. In addition, Kakar, Means \& Tash (1983) have suggested that the control of flagellar motility might well be mediated through the cAMPdependent specific phosphorylation of an ubiquitous flagellar protein of molecular weight 55000 .

A concerted regulation of sperm motility by calmodulin and cAMP-dependent protein kinase activity has been postulated by Tash \& Means (1982). In addition, these authors provided data in agreement with an inhibitory role of calmodulin in the sperm flagellar beat. Indeed, an inverse relationship between the motility index of the different sperm samples and sperm intracellular calmodulin concentration can be shown from our data. However, comparison of the pattern of sperm calmodulin levels between the abnormal and normal rams seems to rule out a threshold effect of sperm calmodulin concentration determining the onset of flagellar motility.

\section{References}

Autric, F., Ferraz, C., Kilhofer, M.C., Cavadore, J.C. \& Demaille J.G. (1980) Large scale purification and characterization of calmodulin from ram testis; its metal-ion-dependent conformers. Biochim. Biophys. Acta 631, 139-147.

Dacheux, J.L. (1980) An in vitro laminal perfusion technique to study epididymal secretion. IRCS Med. Sci. 8, 137-147.

Dacheux, J.L. \& Paquignon, M. (1980) Relation between the fertilizing ability, motility and metabolism of epididymal spermatozoa. Reprod. Nutr. Develop. 20, 1085-1099.
Dacheux, J.L., Paquignon, M. \& Combarnous, Y. (1983) Head to head agglutination of ram and boar epididymal spermatozoa and evidence for an epididymal antiagglutinin. $J$. Reprod. Fert. 67, 181-189.

Dubois, M., Jouannet, P., Berg, P., Volchine, B., Serres, C. \& David, G. (1975) Méthode et appareillage de mesure objective de la motilité des spermatozoïdes humains. Annls Physiol. Biol. Med. 9, 19-41.

Feinberg, J., Weinman, J., Weinman, S., Walsh, M., Harricane, M., Gabrion, J. \& Demaille, J. (1981) Immunocytochemical and biochemical evidence for the presence of calmodulin in bull sperm flagellum. 
Isolation and characterization of sperm calmodulin. Biochim. Biophys. Acta 673, 303-311

Feinberg, J., Pariset, C., Rondard, M., Loir, M., Lanneau, M., Weinman, S. \& Demaille, J. (1983) Evolution of $\mathrm{Ca}^{2+}$ and cAMP-dependent regulatory mechanisms during ram spermatogenesis. Devl Biol. 100, 260-265.

Garbers, D.L., Hansbrough, J.R., Radany, E.W., Hyne, R.V. \& Kopf, G.S. (1980) Purification and characterization of calmodulin from sea urchin spermatozoa. $J$. Reprod. Fert. 59, 377-381.

Glynn, I.M. \& Chappell, J.B. (1964) A simple method for the preparation of $\left[{ }^{32} \mathrm{P}\right]$ labelled adenosine triphosphate of high specific activity. Biochem. J. 90, 147149.

Haiech, J., Klee, C.B. \& Demaille, J.G. (1981) Effects of cations on affinity of calmodulin for calcium: ordered binding of calcium ions allows the specific activation of calmodulin stimulated enzymes. Biochemistry, N.Y. 20, 3890-3897

Horowitz, J.A., Toeg, H. \& Orr, G.A. (1984) Characterization and localization of cAMP-dependent protein kinases in rat caudal epididymal sperm. $J$. biol. Chem. 259, 832-838.

Hoskins, D.D., Casillas, E.R. \& Stephens, D.T. (1972) Cyclic AMP-dependent protein kinases of bovine epididymal spermatozoa. Biochem. Biophys. Res. Commun. 48, 1331-1338.

Imai, H., Niwa, K. \& Iritani, A. (1977) Penetration in vitro of zona-free hamster eggs by ejaculated spermatozoa. J. Reprod. Fert. 51, 495-497.

Jones, H.P., Lenz, R.W., Palewitz, B.A. \& Cormier, M.J. (1980) Calmodulin localization in mammalian spermatozoa. Proc. natn. Acad. Sci. U.S.A. 77, 27722776.

Kakar, S.S., Means, A.R. \& Tash, J.S. (1983) Initiation of flagellar motility requires the cAMP-dependent phosphorylation of a 55000 dalton protein. J. Cell Biol. 748, 197, Abstr.

Kakiuchi, S., Yasuda, S., Yamazaki, R., Teshima, Y., Kanda, K., Kakiuchi, R. \& Sobue, K. (1982) Quantitative determinations of calmodulin in the supernatant and particulate fractions of mammalian tissues. $J$. Biochem., Tokyo 92, 1041-1048.

Le Peuch, C.J., Ferraz, C., Walsh, M.P., Demaille, J.G. \& Fischer, E. (1979) Calcium and cyclic nucleotide dependent regulatory mechanisms during development of chick embryo skeletal muscle. Biochemistry, N.Y. 18, 5267-5273.

Maita, T., Umegane, T., Kato, Y. \& Matsuda, G. (1980) Aminoacid sequence of the $\mathrm{L}_{1}$ light chain of chicken cardiac muscle myosin. Eur. J. Biochem. 107, 565575.

Orgebin-Crist, M.C., Olson, G.E. \& Danzo, B.J. (1981) Factors influencing maturation of spermatozoa in the epididymis. In Intragonadal Regulation of Reproduction, pp. 399-417. Eds C. Chaning \& P. Franchimont. Academic Press, New York.

Pariset, C.C., Roussel, C., Weinman, S.J. \& Demaille J.G. (1983) Calmodulin intracellular concentration and cAMP-dependent protein kinase activity in human sperm samples in relation to sperm morphology and motility. Gamete Res. 8, 171-182.

Perrie, W.T., \& Perry, S.V. (1970) An electrophoretic study of the low molecular weight components of myosin. Biochem. J. 119, 31-38.

Tash, J.S. \& Means, A.R. (1982) Regulation of protein phosphorylation and motility of sperm by cyclic adenosine monophosphate and calcium. Biol. $R e$ prod. 26, 745-763.

Tash, J.S. \& Means, A.R. (1983) Cyclic adenosine 3'5'monophosphate, calcium and protein phosphorylation in flagellar motility. Biol. Reprod. 28, 75-104.

Walsh, M.P., Vallet, B., Cavadore, J.C. \& Demaille, J.G. (1980) Homologous calcium binding proteins in the activation of skeletal cardiac and smooth muscle myosin light chain kinases. J. biol. Chem. 255, 335337.

Witt, J.J. \& Roskoski, R. (1975) Rapid protein kinase assay using phosphocellulose paper absorption. Analyt. Biochem. 66, 253-258.

Received 16 July 1984 